\title{
Effects of Single-Drop Impactions and Natural and Simulated Rains on the Dispersal of Botryosphaeria dothidea Conidia
}

\author{
Neph Ahimera, Simon Gisler, David P. Morgan, and Themis J. Michailides
}

First, third, and fourth authors: Department of Plant Pathology, University of California-Davis, Parlier 93648; and second author: visiting student, Swiss Federal Institute of Technology ETH Zürich, Switzerland.

Accepted for publication 25 June 2004.

\section{ABSTRACT}

Ahimera, N., Gisler, S., Morgan, D. P., and Michailides, T. J. 2004. Effects of single-drop impactions and natural and simulated rains on the dispersal of Botryosphaeria dothidea conidia. Phytopathology 94:1189-1197.

Laboratory and field experiments were conducted to study the dispersal of Botryosphaeria dothidea conidia using single-drop impactions and natural and simulated precipitations. For laboratory studies, 200 single drops were released from a height of $1 \mathrm{~m}$ on infected pistachio nuts. On pieces of photographic film, $50 \%$ of the droplets were collected within $20 \mathrm{~mm}$ (average droplet travel distance) of the target area, and the droplets ranged from 0.041 to $3.19 \mathrm{~mm}$ in diameter, with an average of $0.3 \mathrm{~mm}$. Each droplet carried an average of $23 \mathrm{~B}$. dothidea conidia. In 3 years of field experiments, rainwater was collected in funnels connected to bottles positioned at different heights inside the tree canopy and at different distances away from the edge of tree canopy in three commercial pistachio orchards in San Joaquin, Yolo, and Glenn counties in California. Numbers of conidia in rainwater varied among and within sampling seasons by sampling dates and orchards. Up to 67,000 conidia/ml were obtained in rainwater samples collected from an orchard in Yolo County. Rainwater from orchards in Yolo and Glenn counties contained a consistently higher number of conidia than rainwater collected from the orchard in San Joaquin County. Variation in numbers of conidia also existed among heights where bottles were located. There were significantly more conidia in rainwater collected inside than outside tree canopies. Inside tree canopies, bottles located at 100 and $150 \mathrm{~cm}$ above ground collected more $B$. dothidea conidia than those placed at 50 and $200 \mathrm{~cm}$. Conidia were collected as far as $1 \mathrm{~m}$ from the tree canopy edge. Based on data from the Glenn County orchard, a linear relationship between number of conidia $(Y)$ and rainfall amount $(X)$ in millimeters was determined as $Y=240 X-$ 3,867 , with $r^{2}=0.91$, which meant that a minimum of $16.1 \mathrm{~mm}$ of rain was needed to disperse conidia of $B$. dothidea. The power law model best described the dispersal gradients of $B$. dothidea propagules in the 19992000 and 2001-02 sampling seasons, with $r^{2}$ values of $\geq 0.73$, whereas the exponential law model fit best for the 2000-01 data, with $r^{2}$ values of $\geq 0.81$. In a rain simulation experiment, the intensity of the rain generated by a nozzle at $138 \mathrm{kPa}$ of pressure inside the tree canopy was approximately five times higher than rain recorded outside the tree canopy. Rain removed up to $65 \%$ of conidia from infected fruit. These results confirmed that $B$. dothidea is a splash-dispersed pathogen with relatively short distances of spore dispersal within pistachio orchards. Only pycnidia are present in pistachio orchards; therefore, the results also indicate that inoculum of $B$. dothidea should be entirely splashed dispersed.

Additional keywords: panicle and shoot blight, Pistacia vera.
The pistachio (Pistacia vera L.) is a deciduous, subtropical nut tree, native to Asia and Asia Minor, requiring winter chilling for good fruit production $(35,40)$. The most successful production areas have long, hot, dry summers, with over 2,000 heat units (hours with temperature above $21^{\circ} \mathrm{C}$ ) during the growing seasons. Pistachio was introduced into the United States in 1854 but commercial production did not start until 1929.

No serious diseases have been reported on pistachio in Turkey or Iran, countries where pistachio production is important (35). However, in California pistachio trees, a severe panicle and shoot blight disease, caused by a Fusicoccum sp., anamorph of Botryosphaeria dothidea (Moug.:Fr.) Ces. \& De Not., was first described in 1984 (37). It has become one of the most important diseases in northern and central California (26). Initially, only pistachio trees grown in the Sacramento Valley were affected (17); however, in 1995 and 1996, severe epidemics of the disease were observed in the San Joaquin Valley, resulting in substantial yield loss in fruit quantity and quality in orchards. Although panicle and shoot blight losses in the San Joaquin Valley were minimal in 1997, yield losses continued to be severe in the Sacramento Valley orchards, especially in 1998 (22). The disease causes significant direct losses by killing fruit panicles (18) and is

Corresponding author: T. J. Michailides; E-mail address: themis@ uckac.edu

Publication no. P-2004-0824-01R

(C) 2004 The American Phytopathological Society now considered as the most serious threat to pistachio trees grown in California.

$B$. dothidea is an ascomycete fungus that is difficult to control once it is established in a pistachio orchard (20). The pathogen produces pycnidia within the bark, where fungicides cannot reach. $B$. dothidea overwinters subdermally in pycnidia developed on retained rachises, fruit mummies, petioles, buds, and cankers of blighted shoots and panicles (17). Cankers constitute the main sources of primary inoculum by providing pycnidiospores for at least 6 years (25). Infections occur during the rainy season (winter to early spring) and remain latent until later in the season (June through August), when symptoms of the disease appear. Under favorable conditions during August, the disease can increase suddenly on infected clusters and kill them within 4 weeks (25). Previous research has shown that careful and systematic winter pruning of blighted twigs, shoots, and clusters $\approx 5 \mathrm{~cm}$ below the canker can reduce panicle and shoot blight (25). B. dothidea sporulates profusely on dead branches left in trees or on the orchard floor; therefore, removal and or burning of this food source is essential to reduce the inoculum level in an orchard. Although farm equipment is known to spread some plant diseases, pycnidiospores of $B$. dothidea were not dispersed by pruning shear (30). However it has been recommended to stop pruning during rain events to avoid any possible contamination of fresh pruning wounds by rainsplashed conidia (30).

Rain plays a very important role in the spread and development of panicle and shoot blight in orchards. Rainwater dripping from 
pistachio trees from orchards in Butte and Glenn counties in the fall contained up to 13,000 and 23,250 pycnidiospores per milliliter, respectively (20). Therefore, buds and other plant organs which come in contact with rainwater can be coated with conidia of the pathogen $(1,29)$ if the tree has panicle and shoot blight. Other studies showed that pycnidiospores needed splashing rain or sprinkler irrigation water $(19,27)$, or other vectors such as insects or birds, to spread the pathogen's propagules from one plant or plant part to another (21). Because rain usually does not fall during late spring and summer in the Central Valley, spore dispersal and infections must occur during the rainy season (fall to early spring) and remain latent until suitable conditions for symptom development occur late in season. Winter rains were found to contribute to natural infections of apple and peach buds by $B$. obtusa $(4,5,7,39,44)$. The objectives of this study were to determine the effects of (i) single water drops in dispersing spores from mature pycnidia of $B$. dothidea on pistachio fruit, (ii) natural rains in dispersing spores from pycnidia on pistachio fruit, and (iii)

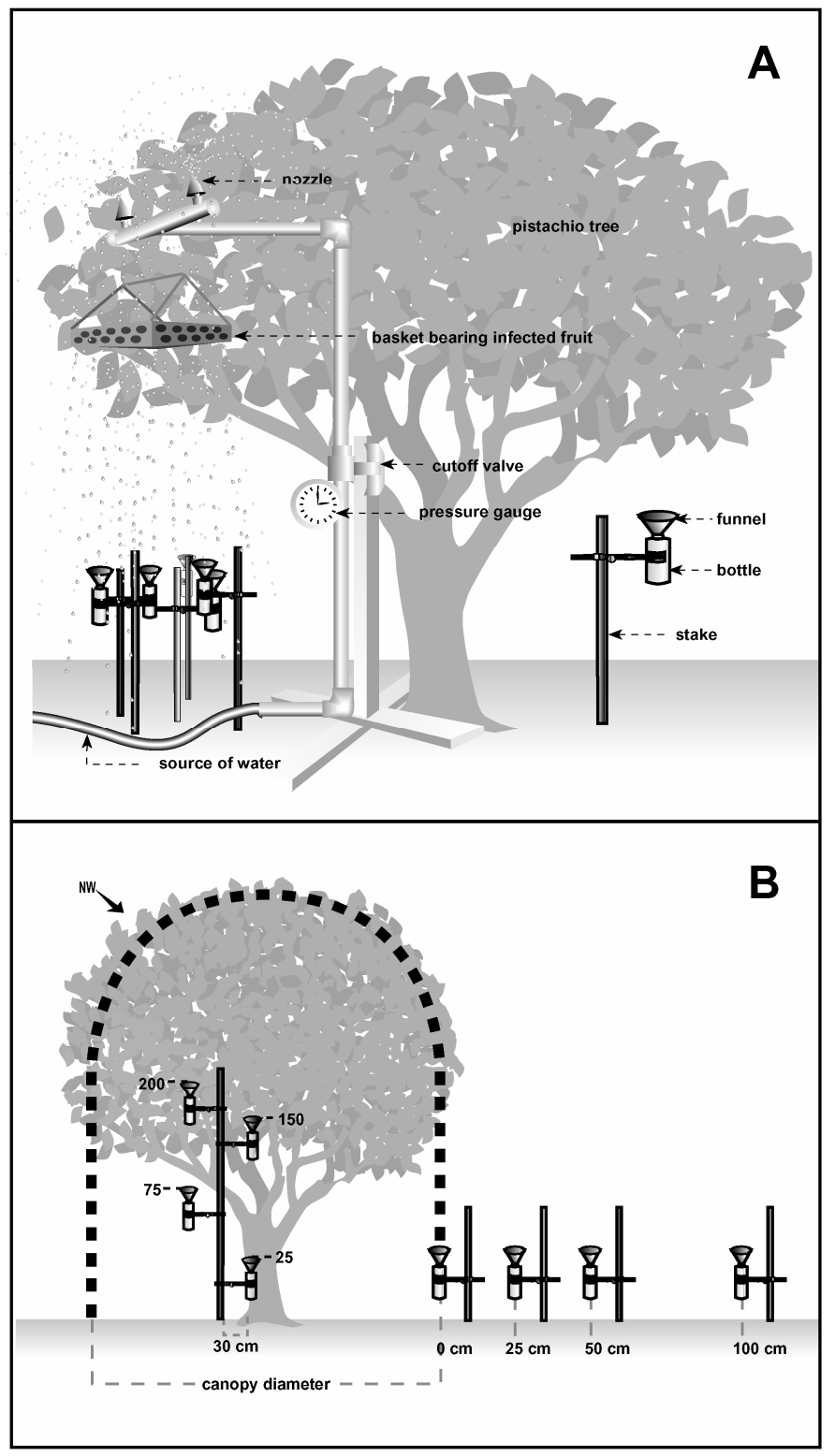

Fig. 1. Diagram showing the setup in the field to determine dispersal and collection of conidia of Botryosphaeria dothidea causing panicle and shoot blight of pistachio under $\mathbf{A}$, simulated rain in an experimental orchard at Kearney Agricultural Center, in Parlier, CA and $\mathbf{B}$, natural rains in three commercial pistachio orchards located in Glenn, San Joaquin, and Yolo counties. simulated rainwater on the dispersal of $B$. dothidea conidia. We also wanted to determine how much rain water was needed to initiate spore dispersal and the distances outside tree canopies and the various heights spores could be dispersed within tree canopies.

\section{MATERIALS AND METHODS}

Single-drop experiments. To detect conidia in splash droplets, the photographic film technique developed by Fitt et al. (10) was followed. Splash droplets, produced by single drops falling from a height of $100 \mathrm{~cm}$ onto infected pistachio nut with pycnidia exuding conidia, were collected on $6-b y-2.5-\mathrm{cm}$ pieces of photographic film. A total of 200 uniform single drops $(3 \mathrm{~mm}$ in diameter) of water were generated with a $20-\mathrm{ml}$ syringe. Five film pieces were aligned on one side of the nut covering a distance of $30 \mathrm{~cm}$ from the nut. The nut was replaced every 60 drops to avoid spore depletion. The first and second film pieces were replaced after every twentieth and hundredth drop, respectively. Then the film pieces were dried and examined under a compound microscope $(\times 100)$. The number of splashed droplets, their size, and distance of travel from the nut source were measured and the number of conidia they carried was counted. The diameter of droplets on the photographic film was corrected using the spread factor $(=0.56)$ determined by Fitt et al. (10). The experiment was repeated three times.

Rain simulation experiments. A rain simulation system was installed in a pistachio tree at the Kearney Agricultural Center (KAC) experimental orchard to determine effects of rain on spore dispersal. The sprinkling system was constructed using a schedule-40 PVC pipe. A 3.5-m water pipe was erected among the branches of a pistachio tree on which a wire basket ( 66 by 60 by $7.5 \mathrm{~mm}$ in size) was hung (Fig. 1A). Five similar-size fruit naturally infected by $B$. dothidea and covered with pycnidia were placed in the basket (one in each corner and one in the middle). The top of the water pipe had two water outlets to achieve an even application of water at the target area. A pressure gauge was installed at $\approx 2 \mathrm{~m}$ above the ground to monitor water pressure and adjust the volume of water being applied. Fan-type sprinkler heads (nozzles) with a T-40 orifice were attached to the water outlets. They were pointing upward so that water reaches zero velocity before falling freely to the ground. Five bottles with a funnel per bottle attached to a $1-\mathrm{m}$ metal pole $\approx 25 \mathrm{~cm}$ above the ground surface were positioned under the wire basket to collect spores dispersed by the simulated rain falling onto the fruit with pycnidia (Fig. 1A). Two sprinkling nozzles (15F and $8 \mathrm{~F}$ ) were used in the experiment to generate two different rain intensities. For each nozzle, the rain simulation was repeated at least three times. Collected water was brought to the laboratory and the conidia concentration was estimated as described above. To determine the raindrop size distribution under the tree canopy, watersensitive papers (Spraying Systems Co., Wheaton, IL) attached to cardboard were exposed to the rain manually for $\approx 1 \mathrm{~s}$ and allowed to dry. The diameter of $\approx 100$ representative drop traces was measured and the diameter of raindrop was calculated based on the spread factor of 2.1 as determined by the manufacturer for drop traces of diameter greater than $0.4 \mathrm{~mm}$.

Quantification of levels of $B$. dothidea conidia in natural rainwater. An experiment was conducted in commercial pistachio orchards in San Joaquin, Yolo, and Glenn counties to quantify $B$. dothidea conidia collected in rainwater within tree canopies between fall 1999 and spring 2002. Before initiation of the rainy season, $7.5-\mathrm{cm}$-diameter plastic funnels connected by rubber stoppers to $250-\mathrm{ml}$ plastic bottles were attached to a metal pole at 50,100,150, and $200 \mathrm{~cm}$ above the soil surface within a pistachio tree canopy at a distance of $0.3 \mathrm{~m}$ from the tree trunk (Fig. 1B). One bottle was used for each height and four trees (replications) were used per orchard. To determine how far $B$. dothidea 
conidia could be dispersed from the tree canopy, similar bottles with funnels also were attached to poles $25 \mathrm{~cm}$ above the soil surface and the poles were placed on the ground at $0,25,50$, and $100 \mathrm{~cm}$ away from the projected outer perimeter of the tree canopy (Fig. 1B). For distance dispersal, three tree replications at the orchard border were used per site. Because $B$. dothidea conidia start to germinate within $2 \mathrm{~h}$ when they come in contact with water (17), $0.15 \mathrm{~g}$ of copper sulfate was added in each bottle prior to the experiment setup to prevent spore germination. The bottles filled with rainwater were collected during the rainy season following significant rain events, taken to the laboratory, and replaced with similar empty bottles in the three orchards. In the laboratory, bottles were allowed to stand still for at least $24 \mathrm{~h}$ to allow conidia to settle to the bottom of the bottle and the quantity of water collected was calculated based on the internal diameter of the bottle and the height of the water in each bottle (volume for a cylinder). Excess rainwater was carefully removed from each bottle with a Pasteur pipette attached to a vacuum line. The $30 \mathrm{ml}$ of water remaining at the bottom of the bottle was thoroughly mixed and centrifuged at $6,600 \times g$ for 5 min (Sorvall Superspeed Centrifuge, Ivan Sorvall, Inc. Norwalk, CT). The supernatant again was vacuum removed. No spores were found in the supernatant after repeated examinations with a compound microscope. A volume of $1 \mathrm{ml}$ remaining at the bottom was vortexed for $5 \mathrm{~s}$ to resuspend spores and stored for spore concentration counts. The concentration of conidia in the suspension was estimated by averaging counts of five 1-mm hemacytometer squares performed with the aid of a compound microscope $(\times 250)$.

Data analysis. The results from the single-drop experiments were analyzed with regression using PROC REG procedure of SAS software (SAS Institute, Cary, NC). Graphs were generated with Sigma Plot (version 8.0; Systat Software, Inc., Point Richmond, CA).

The experiment on the quantification of $B$. dothidea conidia under natural conditions in orchards was a repeated-measure design with orchard as main effect source of variation because orchards would be expected to have different amounts of spore sources due to different observed disease levels. Sampling dates were repeated measures over years. Data from inside the tree canopy were analyzed separately from those outside the tree canopy. For each sampling date, mean number of conidia per site was calculated and compared among heights within the tree canopy or distances from the canopy edge with the Fisher's protected least significant difference (LSD) test using the PROC GLM procedure of the SAS software package (SAS Institute).

Weather data for each site were accessed from the integrated network of computerized weather stations of the California Irrigation Management Information System (CIMIS) located at or near the three orchards and were summarized daily. The cumulative amount of precipitation corresponding to the rain events that produced rainwater collected in the bottles was calculated. A regression analysis was performed to determine relationships between the numbers of $B$. dothidea conidia (dependent variable) and total amount of precipitation (independent variable) corresponding to each sampling date recorded in each orchard using the PROC REG procedure of SAS.

Numbers of conidia outside the tree canopy were fit to the power law model (12) and the exponential model (28) to determine the pattern of the dispersal gradients. The power law model is described as $Y=A_{\mathrm{P}} S^{-\mathrm{Bp}}$, which linearized becomes $\ln (Y)=$ $\ln \left(A_{\mathrm{P}}\right)-B_{\mathrm{P}} \ln (S)$. The exponential model is $Y=A_{\mathrm{E}} \exp \left(-B_{\mathrm{E}} S\right)$ or $\ln (Y)=\ln \left(A_{\mathrm{E}}\right)-B_{\mathrm{E}} S(6)$, where $Y$ is the number of conidia at the source, $S$ is the distance, and $A_{\mathrm{P}}, A_{\mathrm{E}}, B_{\mathrm{P}}$, and $B_{\mathrm{E}}$ are the intercepts and the gradients (rates of decrease in $Y$ with distance or slopes) of the power law and exponential model, respectively. The parameter $B_{\mathrm{P}}$ is dimensionless, whereas $B_{\mathrm{E}}$ has the dimension of length ${ }^{-1}$.

\section{RESULTS}

Single-drop experiment. The 200 single drops produced a total of 568 droplets carrying a total of $1.3 \times 10^{4}$ conidia. One droplet carried, on average, $23 \mathrm{~B}$. dothidea conidia. The median travel distance (distance traveled by $50 \%$ of droplets) was $20 \mathrm{~mm}$ (Fig. 2A). Only 6\% of droplets were splashed further than $100 \mathrm{~mm}$ and carried $0.5 \%$ of the total conidia dispersed. Fewer than $0.2 \%$ of droplets reached $300 \mathrm{~mm}$. A spike of conidia/droplet was obtained in droplets collected at $55 \mathrm{~mm}$ away from the source (Fig. 2B), suggesting splashing of parts or entire cirrhi from pycnidia. More than $56 \%$ of conidia were carried in droplets that landed within $15 \mathrm{~mm}$ of the inoculum source (Fig. 2B). Because the majority droplets splashed at a distance of $60 \mathrm{~mm}$ had more
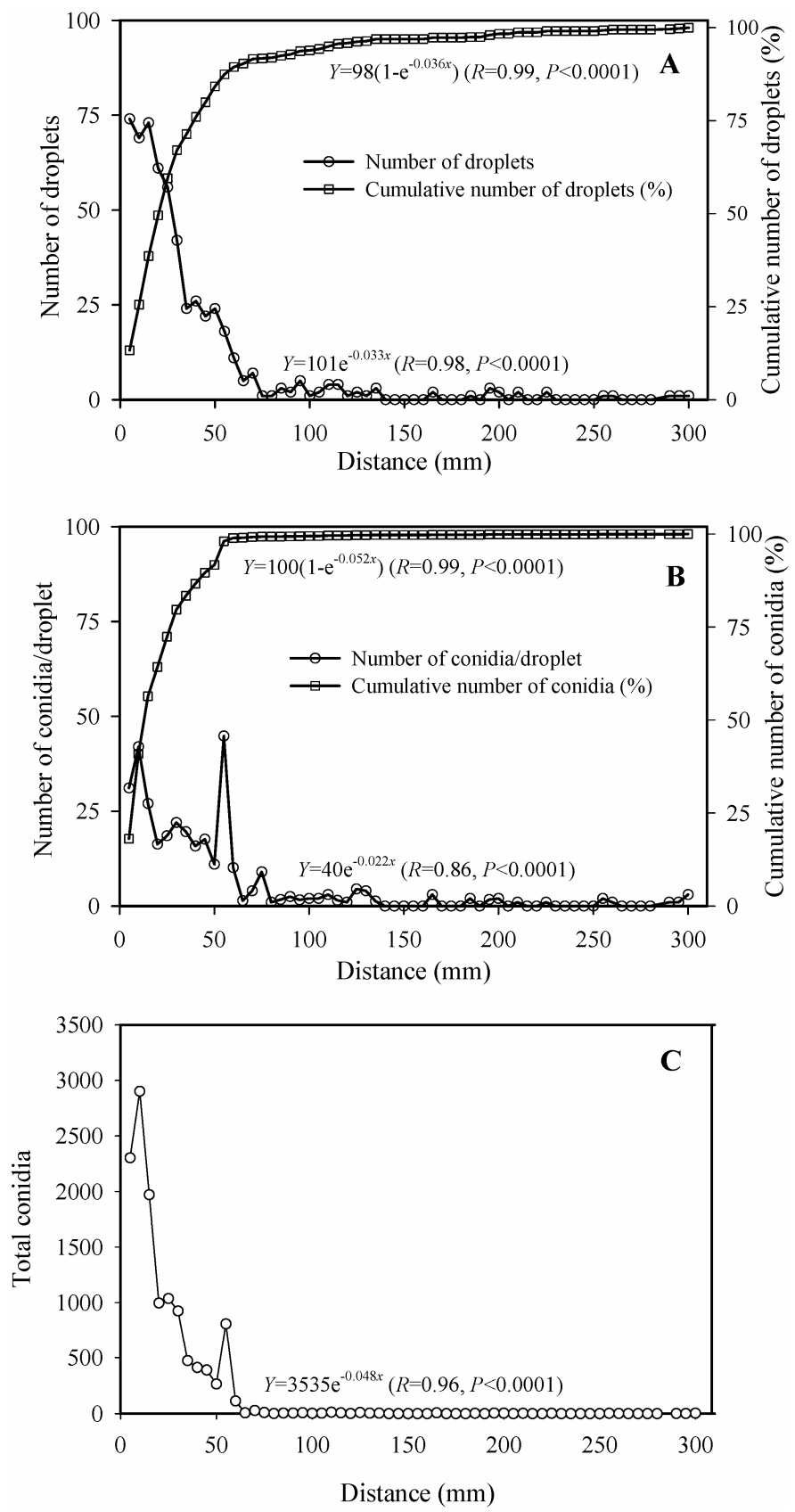

Fig. 2. Distribution by droplet travel distance of $\mathbf{A}$, the number and cumulative percentage of splash droplets, $\mathbf{B}$, conidia per droplet and cumulative percentage of conidia, and $\mathbf{C}$, total number of conidia which were splash dispersed by 2003 -mm-diameter single drops released from a height of $100 \mathrm{~cm}$ above a pistachio nut bearing pycnidia of Botryosphaeria dothidea. (Spike at $55 \mathrm{~mm}$ revealed splashed parts of cirrhi, pycnidia, or both within the water drops.) 
than 10 conidia per droplet, the majority of the conidia essentially were splashed at a distance of $60 \mathrm{~mm}$ from the source (Fig. 2C). The patterns of number of droplets, number of conidia per droplet, and total conidia versus distance were similar, as shown by the three exponential decay equations (Fig. 2A to C), and the cumulative percentage of the number of droplets and conidia also were similar and followed an exponential increase (Fig. 2A and B). More than $95 \%$ of the conidia counted were splashed at a distance of $60 \mathrm{~mm}$ from the source.

The droplet diameter ranged between 0.041 and $3.19 \mathrm{~mm}$, with an average of $0.3 \mathrm{~mm}$ (Fig. 3A). The number of conidia per droplet of different sizes ranged between 0 and 300, with an average of 23 conidia per droplet. Of these droplets, $23 \%$ carried just one conidium, while droplets $0.85 \mathrm{~mm}$ in diameter and those smaller than $0.85 \mathrm{~mm}$ carried $50 \%$ of conidia (Fig. 3B). In all,
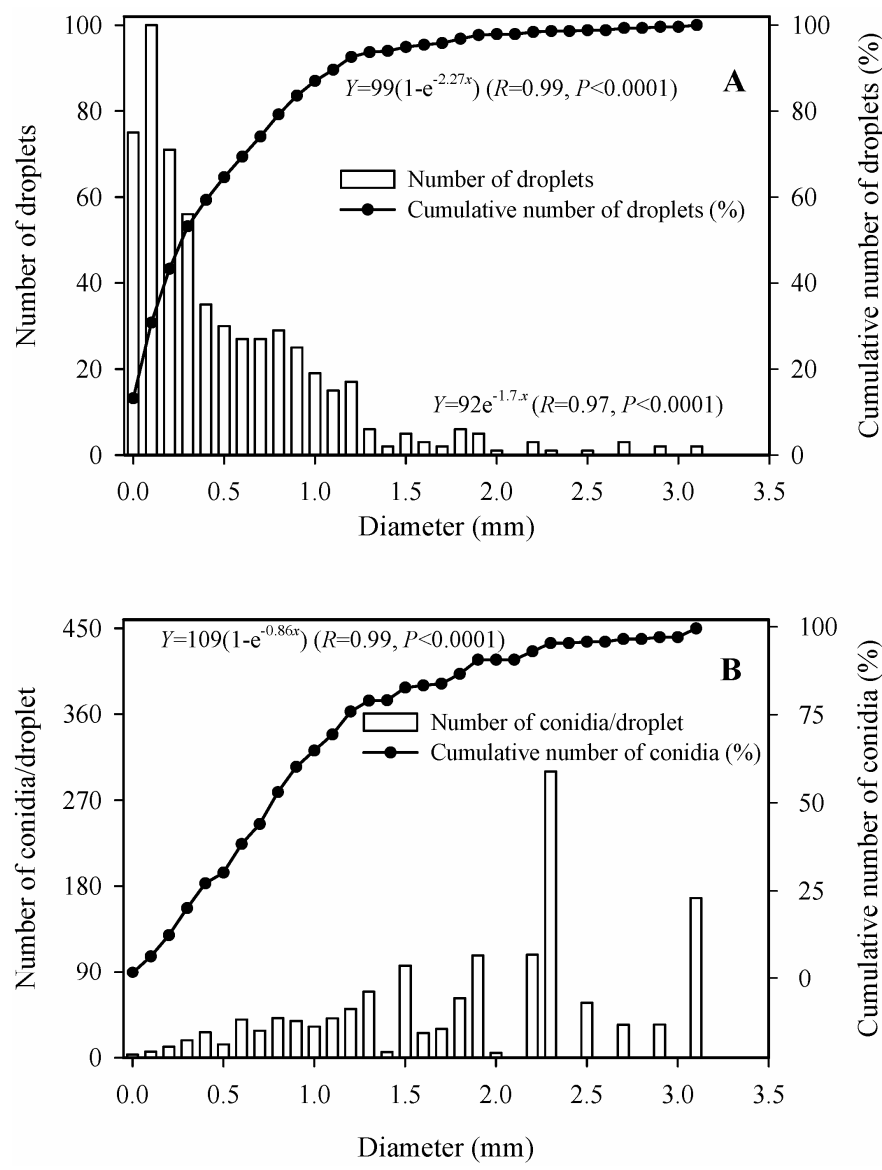

Fig. 3. Distribution by droplet diameter of $\mathbf{A}$, the number and cumulative percentage of splash droplets and $\mathbf{B}$, conidia per droplet and cumulative number of conidia which were splash dispersed by 2003 -mm-diameter single drops released from a height of $100 \mathrm{~cm}$ above a pistachio bearing pycnidia of Botryosphaeria dothidea. $\approx 2.3 \%$ of droplets had a diameter of $\geq 2 \mathrm{~mm}$ and carried $9 \%$ of conidia, whereas $13 \%$ of the droplets had a diameter of $<0.1 \mathrm{~mm}$ and carried $1.8 \%$ of conidia. The cumulative number of droplets and of conidia calculated as percentages of the totals versus the droplet diameter followed an exponential increase $(R=0.99$; Fig. $3 \mathrm{~A}$ and $\mathrm{B})$. The distribution of number of conidia per droplet was skewed to the right due to the few large droplets that carried many conidia (when parts of cirrhi or pieces of pycnidia were splashed) (Fig. 3B).

Rain simulation experiment. For both types of sprinkling nozzles, the amount of artificial rain inside the tree canopy (Fig. 1A) was approximately five times higher than the simulated rain outside the tree canopy. For the larger nozzle $(15 \mathrm{~F})$ at $138 \mathrm{kPa}$, the distribution of the drop diameter ranged between 0.2 and $2.4 \mathrm{~mm}$ outside the tree canopy (Table 1). Within the tree canopy, a few drops $(2.7 \%)$ reached a diameter of $>5 \mathrm{~mm}$ due to collection and drip from leaves. The small nozzle $(8 \mathrm{~F})$ at high water pressure $(207 \mathrm{kPa})$ resulted in larger amount of rain than the larger nozzle $(15 \mathrm{~F})$ at lower pressure. With the $15 \mathrm{~F}$ nozzle at $138 \mathrm{kPa}, 65 \%$ of spores were removed from fruit, but only $14 \%$ of those spores were collected in the bottles (Table 1). Fewer spores $(\approx 5 \%)$ were removed from fruit exposed to rain generated by the 8 F nozzle and only $12 \%$ collected in bottles.

Number of $\boldsymbol{B}$. dothidea conidia inside tree canopy. For the 1999-2000 sampling, there were highly significant differences in conidia captured in bottles $(P<0.0001)$ among orchards as well as among sampling dates. Rainwater collected on 25 April 2000 contained more conidia than other sampling dates (Fig. 4A). The highest number of conidia $(67,000$ conidia) was obtained in rainwater samples collected from an orchard in Yolo County. Except for the sampling performed on 9 March 2000, rainwater collected from the orchard in Yolo County contained consistently more $B$. dothidea conidia than rainwater collected from orchards in Glenn and San Joaquin counties. The orchard in San Joaquin County had the smallest number of conidia, with the maximum of 19,000 conidia collected on 25 April 2000. Variation in the numbers of conidia also existed among heights where bottles were located. Bottles placed at $200 \mathrm{~cm}$ above the ground contained a lower number of conidia than bottles positioned 50, 100, and $150 \mathrm{~cm}$ high (Fig. 5A). No significant differences were detected in the number of spores collected at the latter three heights.

In 2000-01, the total number of B. dothidea conidia was lower than that collected in 1999-2000 and varied significantly $(P<$ $0.0001)$ among orchards and sampling dates. The highest numbers of conidia $(23,000$ and 16,000 conidia) were obtained in rainwater collected in orchards in Glenn and Yolo counties, respectively (Fig. 4B) on 1 May 2001, 10 days after a 25-mm rain had fallen. Bottles located at $200 \mathrm{~cm}$ above the ground contained fewer numbers of spores than those placed at other heights (Fig. $5 \mathrm{~B})$. Bottles placed at $150 \mathrm{~cm}$ above the ground contained significantly $(P<0.0001)$ greater numbers of conidia than bottles placed at 50 and $100 \mathrm{~cm}$.

In 2001-02, the numbers of conidia were similar to those obtained in the previous season. Up to 23,000 and 27,000 B. dothidea

TABLE 1. Characteristics of simulated rain produced with two spray nozzles inside and outside a pistachio tree canopy ${ }^{\mathrm{a}}$

\begin{tabular}{|c|c|c|c|c|}
\hline \multirow[b]{2}{*}{ Characteristics } & \multicolumn{2}{|c|}{ Nozzle $15 \mathrm{~F}$ at $138 \mathrm{kPa}$} & \multicolumn{2}{|c|}{ Nozzle $8 \mathrm{~F}$ at $207 \mathrm{kPa}$} \\
\hline & Outside canopy & Inside canopy & Outside canopy & Inside canopy \\
\hline Drop diameter (mm) & 1.02 & 1.5 & ND & ND \\
\hline Drop diameter range $(\mathrm{mm})$ & $0.2-2.4$ & $1.0-7.3$ & ND & ND \\
\hline Rainfall $(\mathrm{mm} / \mathrm{h})$ & 42.5 & 199.6 & 28.5 & 226.2 \\
\hline Initial spore concentration & $3.1 \times 10^{6}$ & $3.1 \times 10^{6}$ & $3.1 \times 10^{6}$ & $3.1 \times 10^{6}$ \\
\hline Spores in bottle & ND & $4.2 \times 10^{5}$ & ND & $3.6 \times 10^{5}$ \\
\hline Spores remaining on fruit & ND & $1.1 \times 10^{6}$ & ND & $2.9 \times 10^{6}$ \\
\hline Percent spores removed from fruit & ND & 64.5 & ND & 5.2 \\
\hline Percent spores collected in bottle & ND & 13.5 & ND & 11.8 \\
\hline
\end{tabular}

a $\mathrm{ND}=$ not determined. 
conidia were obtained in rainwater collected on 14 November 2001 and 14 March 2002, respectively, from bottles placed in the orchard in Yolo County (Fig. 4C). Overall, rainwater collected from bottles placed in the Yolo County orchard contained higher numbers of conidia than that from other orchards. Rainwater from the orchards in Glenn and San Joaquin counties contained $<10,000$ conidia. Bottles located at 50 and $200 \mathrm{~cm}$ above the ground contained fewer numbers of spores than those placed at 100 and $150 \mathrm{~cm}$ (Fig. 5C). Overall, water sampling performed in the early spring when the temperatures were rising (data not shown) contained more conidia than fall or winter samples.

Relationship between $B$. dothidea conidia and rainwater amount. In 1999-2000, the results from the Glenn County orchard showed a highly significant $(P<0.001)$ linear relationship between the number of $B$. dothidea conidia and the amount of rainfall recorded at the Orland CIMIS station. The relationship could be defined as $Y=240 X-3,867$; where $Y$ is the number of conidia of $B$. dothidea and $X$ is the amount of rainfall in millimeters. The correlation coefficient was 0.91 , which meant that $91 \%$ of the variation in spores collected in bottles within the tree canopy during that season could be explained by the variation in rainfall. By solving the equation for $X$, it would take $\approx 16.1 \mathrm{~mm}$ of
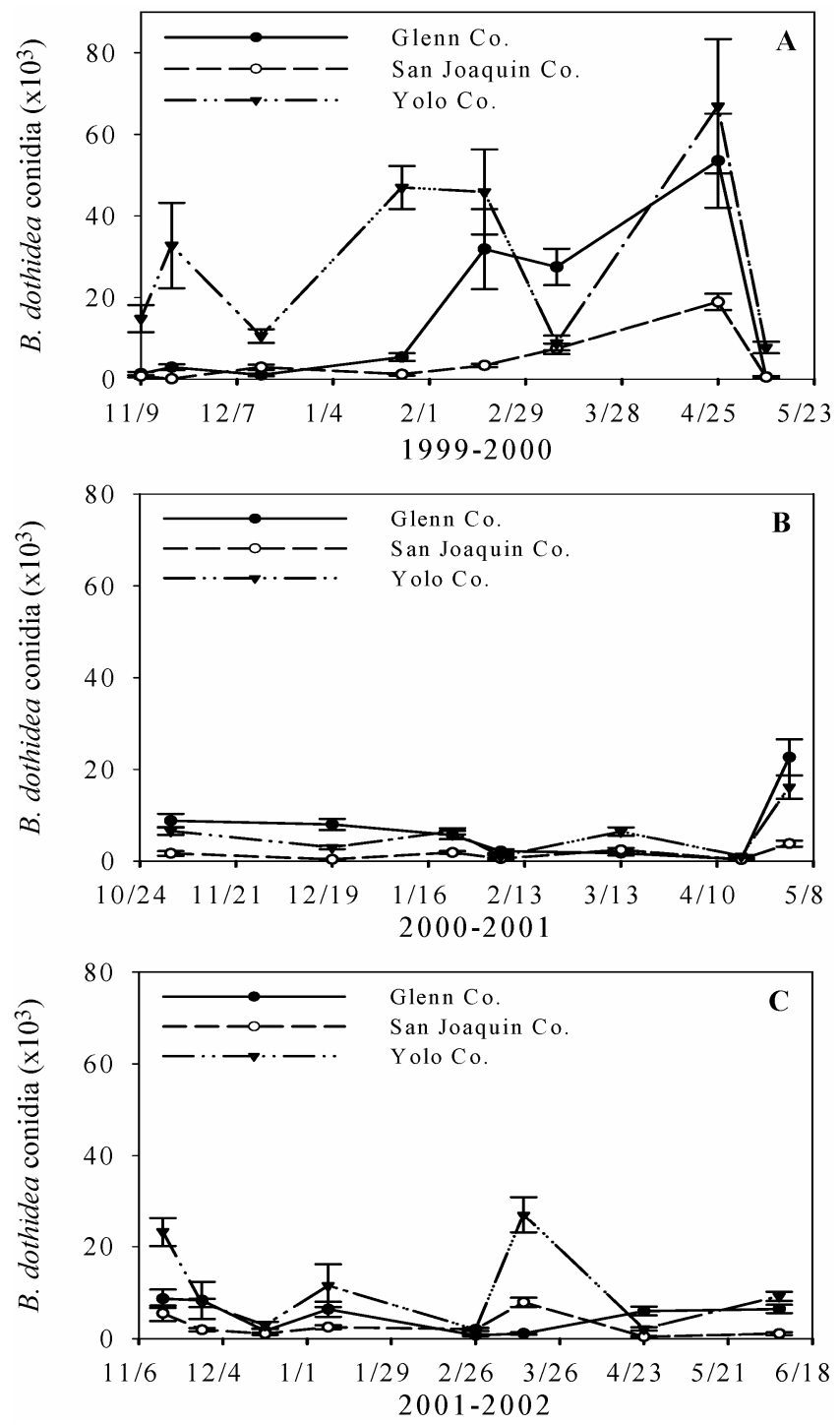

Fig. 4. Number of Botryosphaeria dothidea conidia collected in rainwater inside tree canopy of pistachio trees in three commercial orchards in Glenn, San Joaquin, and Yolo counties between A, November 1999 and June 2000, B, November 2000 and June 2001, and C, November 2001 and June 2002. Vertical bars indicate standard errors. rain before any spore dispersal could occur. No significant relationships were obtained for data in orchards from Yolo and San Joaquin counties, probably due to greater variation in the number of spores collected in different samples at these locations than in Yolo County.

Numbers of $B$. dothidea conidia outside tree canopies. In 1999-2000, the number of $B$. dothidea conidia outside the tree canopy was very low and varied among sampling dates. For orchards in Glenn and San Joaquin counties, there were $<1,000$ conidia/ml of rain except for rainwater samples collected on 9 March 2000. For the orchard in Yolo County, $\approx 10,000$ conidia were collected in rainwater sampled on 25 April 2000. Numbers of conidia decreased as the distance from the tree canopy edge increased (Fig. 6A). Up to 2,000 B. dothidea conidia were collected in bottles located at $100 \mathrm{~cm}$ from the tree canopy edge in the Yolo County orchard, whereas only 365 and 195 conidia were collected in the orchards in Glenn and San Joaquin counties, respectively.

Similar results were obtained for the 2000-01 experiment. For all orchards, the amount of $B$. dothidea conidia was low $(<800$ conidia), except for the collection of 13 March 2001 in Yolo County,
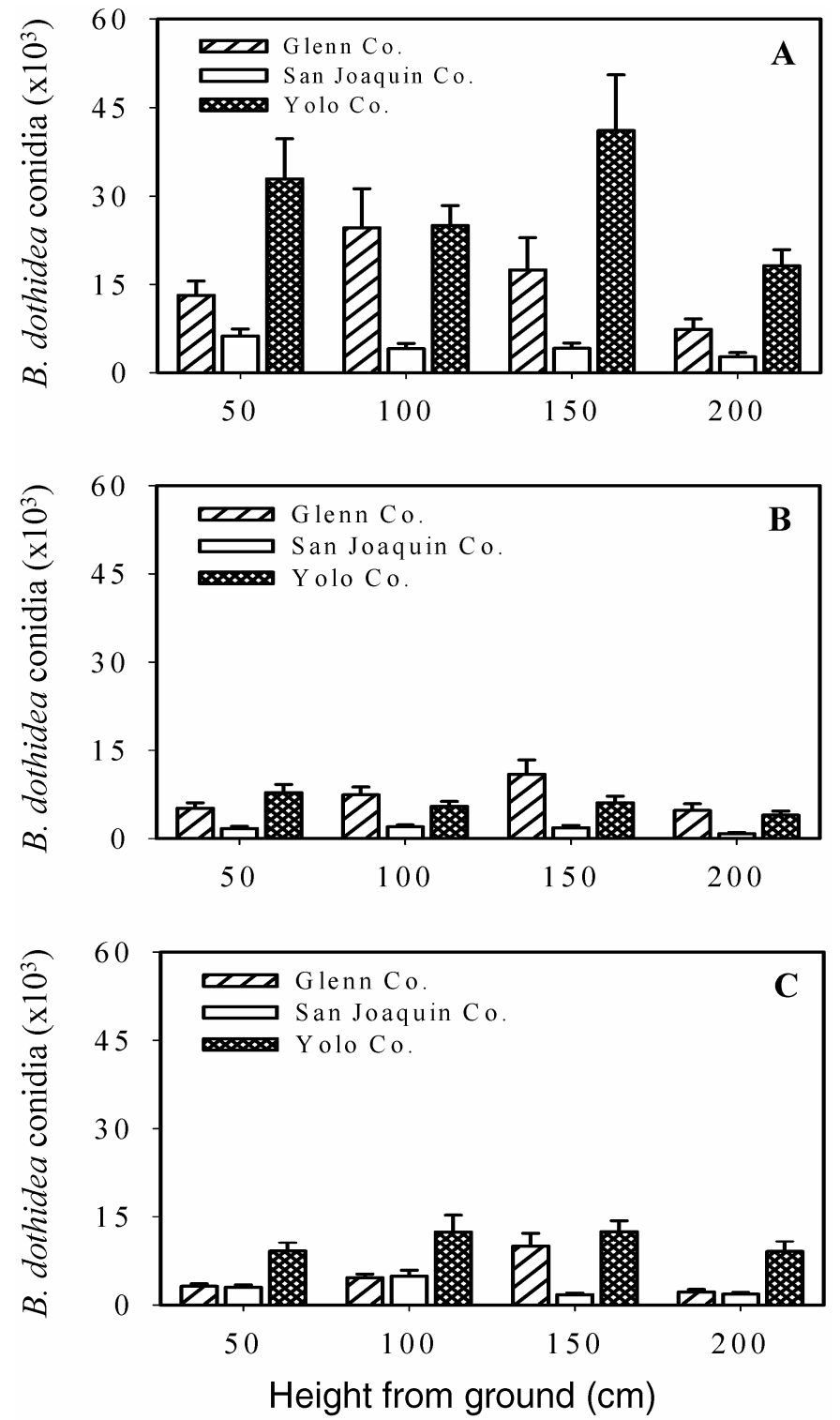

Fig. 5. Number of Botryosphaeria dothidea conidia collected in rainwater at four heights inside tree canopy of pistachio trees in three commercial orchards in Glenn, San Joaquin, and Yolo counties between A, November 1999 and June 2000, B, November 2000 and June 2001, and C, November 2001 and June 2002. Vertical bars indicate standard errors. 

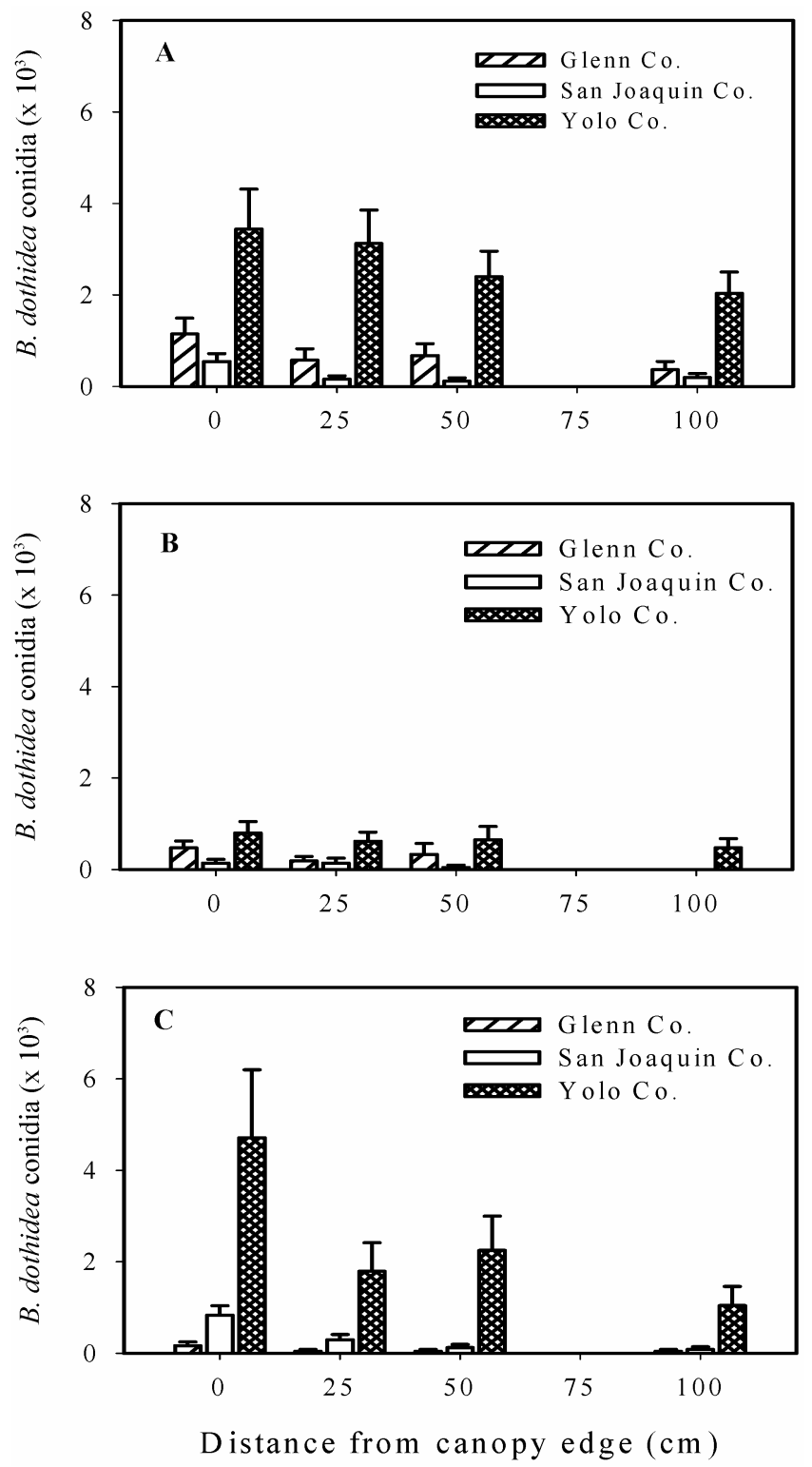

Fig. 6. Number of Botryosphaeria dothidea conidia collected in rainwater at four distances outside tree canopy of pistachio trees in three commercial orchards in Glenn, San Joaquin, and Yolo counties between A, November 1999 and June 2000, B, November 2000 and June 2001, and C, November 2001 and June 2002. Vertical bars indicate standard errors. which had 2,300 conidia/ml of rain. Numbers of conidia decreased as the distance from the tree canopy edge increased. No B. dothidea conidia were obtained in bottles located at $100 \mathrm{~cm}$ away from the edge of the tree canopy, except in Yolo County, where $\approx 500$ conidia were collected (Fig. $6 \mathrm{~B}$ ).

In 2001-02, <700 conidia were obtained in bottles from orchards in Glenn and San Joaquin counties. Samples collected in Yolo County contained up to 10,000 conidia on 14 March 2002. Level of conidia decreased as the distance from the tree canopy increased. Up to 1,000 conidia were dispersed at $100 \mathrm{~cm}$ away from the tree canopy edge in the orchard in Yolo County (Fig. 6C).

Dispersal gradients of $B$. dothidea outside the tree canopies. The power law model best described the dispersal gradients of B. dothidea propagules in 1999-2000 and 2001-02 sampling seasons, with $r^{2}$ values of $\geq 0.73$ (Table 2). Overall, dispersal gradients of $B$. dothidea to as far as $1 \mathrm{~m}$ outside of the outer tree canopy were low $\left(B_{\mathrm{P}}<0.9\right.$ or $\left.B_{\mathrm{E}} \leq 0.06\right)$. For these two seasons, spore dispersal in the orchards in Glenn and San Joaquin counties had less shallow dispersal gradients (larger absolute values of the slopes, $B_{\mathrm{P}}$ ) than the orchard in Yolo County. For the three seasons, the orchard in Yolo had the lowest dispersal gradients overall. In 2000-01, the exponential law model fit best the dispersal gradients for the three orchards, with $r^{2}$ values of $\geq 0.81$. Spore dispersal in orchards in Glenn and San Joaquin counties also showed greater gradients than that of Yolo County. Intercepts (number of conidia at canopy edge) for the two models were similar but varied by orchard. They ranged from 155 (exponential [exp] 5.04) conidia at source to 4,817 (exp 8.48) conidia based on the power law model and from 97 (exp 4.57) conidia to 3,752 (exp 8.23) conidia based on the exponential model (Table 2).

\section{DISCUSSION}

Based on the results from the single-drop experiment, $B$. dothidea conidia were dispersed over short distances from infected pistachio fruit. The median travel distance of the droplets was $20 \mathrm{~mm}$, a third of what was obtained with Phytophthora cactorum on strawberry (45). The number of droplets per impact was smaller than that obtained for Phytophthora cactorum on strawberry fruit. The difference may be due to surface characteristics of the target area (pistachio versus strawberry). The distribution of droplet diameters was skewed to the left and was similar to that found by other researchers $(10,33)$. However, small droplets $(<0.1 \mathrm{~mm})$ carried $\approx 1 \%$ of Pseudocercosporella herpotrichoides (8) compared with $13 \%$ of $B$. dothidea conidia in this experiment. The differences observed between these experiments may be attributed to the biological differences of the pathogens under study such as conidia type, size, and shape.

TABLE 2. Comparison of the parameters of the power law and exponential law models describing the dispersal gradients of Botryosphaeria dothidea conidia outside the canopy of pistachio trees from three commercial orchards between 1999 and $2002^{\mathrm{a}}$

\begin{tabular}{|c|c|c|c|c|c|c|}
\hline \multirow[b]{2}{*}{ Year, orchard } & \multicolumn{3}{|c|}{ Power law model } & \multicolumn{3}{|c|}{ Exponential model } \\
\hline & $\ln \left(A_{\mathrm{P}}\right)$ & $B_{\mathrm{P}}$ & $R_{\mathrm{P}}^{2}$ & $\ln \left(A_{\mathrm{E}}\right)$ & $B_{\mathrm{E}}\left(\mathrm{cm}^{-1}\right)$ & $R_{\mathrm{E}}^{2}$ \\
\hline \multicolumn{7}{|l|}{ 1999-2000 } \\
\hline Glenn & 7.07 & -0.211 & 0.83 & 6.9 & -0.01 & 0.81 \\
\hline Yolo & 8.19 & -0.101 & 0.73 & 8.14 & -0.006 & 0.95 \\
\hline \multicolumn{7}{|l|}{$2000-01$} \\
\hline Glenn & 6.88 & -0.877 & 0.38 & 7.01 & -0.061 & 0.81 \\
\hline Glenn & 5.04 & -0.326 & 0.92 & 4.57 & -0.011 & 0.46 \\
\hline San Joaquin & 6.83 & -0.483 & 0.93 & 6.4 & -0.022 & 0.87 \\
\hline Yolo & 8.48 & -0.283 & 0.85 & 8.23 & -0.013 & 0.79 \\
\hline
\end{tabular}

a Power law model: $\ln (Y)=\ln \left(A_{\mathrm{P}}\right)-B_{\mathrm{P}} \ln (S)$ or $Y=A_{\mathrm{P}} S^{-\mathrm{Bp}}$ and exponential model: $\ln (Y)=\ln \left(A_{\mathrm{E}}\right)-B_{\mathrm{E}} S$ or $Y=A_{\mathrm{E}} \exp \left(-B_{\mathrm{E}} S\right)$, where $Y$ is the number of conidia at the source, $S$ is the distance, and $A_{\mathrm{P}}, A_{\mathrm{E}}, B_{\mathrm{P}}$, and $B_{\mathrm{E}}$ are the intercepts and the gradients (slopes) of the power law and exponential model, respectively. 
In this study, the number of $B$. dothidea conidia varied significantly among orchards, sampling dates, location of collection, and years. Rainwater collected from orchards in Glenn and Yolo counties contained consistently more conidia than rainwater from the orchard in San Joaquin County. This may be because, generally, the disease levels were higher in the orchards in Glenn and Yolo counties than in San Joaquin County (T. J. Michailides, unpublished data), suggesting differences in density of cankers with pycnidia in trees among these orchards. Water sampling performed in the early spring when the temperature was rising contained more conidia than fall or winter sampling. Also, samplings performed between November 1999 and June 2000 contained more conidia than those performed between November 2000 and June 2002. This variation could be attributed to differences in level of inoculum present and amount of precipitation in each orchard. The low level of conidia in rainwater collected in 2000-01 and 2001-02 may be attributed to the pruning of cankered shoots and infected rachises that reduced levels of inoculum in the sampled orchards $(14,23)$.

These results also confirmed that winter and spring rains mainly dispersed $B$. dothidea conidia. More conidia were collected in rainwater when more precipitation had occurred. For instance, the sampling season of 1999-2000 had the highest number of conidia (Fig. 4A) and the highest amount of precipitation in each of the three locations (weather data not shown). Panicle and shoot blight was very severe in the 1998-99 season; therefore, the high level of conidia obtained in the 1999-2000 sampling season could have come from infected tissues of the previous season that were not removed by pruning, because extensive pruning was adapted as a routine practice by growers after 2000 .

The 2000-01 sampling season had the lowest number of conidia (Fig. 4B) and the least precipitation (weather data not shown). These results were in agreement with those obtained in previous research, which showed that rainwater dripping from pistachio trees from orchards in Butte and Glenn counties in the fall contained up to 13,000 and 23,250 pycnidiospores $/ \mathrm{ml}$, respectively (20). The 25,000 conidia/ml appeared to be the "saturation" concentration for high disease development (31). Our rainwater collections recorded up to 60,000 conidia/ml (Fig. 4A). Therefore, buds and other plant tissues, which come in contact with rainwater, can be coated with conidia of the pathogen (1) if the tree had panicle and shoot blight in the previous growing season or seasons. Pycnidia in cankers caused by $B$. dothidea in pistachio can supply conidia for at least 6 years (25). Previous studies confirmed that most bud infections occurred in February or March, when precipitation was usually the highest (29).

As expected, there were significantly higher numbers of conidia in rainwater collected inside the tree canopy than outside. Bottles located at 50 and $200 \mathrm{~cm}$ above the ground within the tree canopy contained fewer spores than those placed at 100 and $150 \mathrm{~cm}$. An explanation for this difference could be that bottles located at the lowest height collected rainwater dripping from the surface of more plant tissues than those located at the 2-m height. Some conidia also may not have been accounted for in bottles located at $50 \mathrm{~cm}$ above the ground due to soil splashed from the ground by storms. Therefore, a sampling at the $100-\mathrm{cm}$ height would have been ideal to collect and determine dispersed spore inoculum of panicle and shoot blight in pistachio tree canopies.

Rainfall is composed of discrete drops that are scattered in a volume of air and subjected to several physical and dynamical processes. Evaporation and drop break-up increase the number of small drops, whereas condensation and coalescence increase the number of large drops (15). Other studies (37) showed that these combined processes produced a drop size ranging from 0.2 to $5.5 \mathrm{~mm}$. For example, during a 1-h storm, the mean drop diameter ranged from 0.5 to $2 \mathrm{~mm}$, but the standard deviation of the diameter varied from one to six times the mean diameter (38). Moreover, the number of drop impacts on the ground ranged between
50 and 5,000 drops $/ \mathrm{m}^{2} / \mathrm{s}$. Although large drops are a small proportion of the total number of drops in a rain, they contribute a large proportion of total rainfall volume and are the main cause of splash dispersal in B. dothidea. Therefore, the size distribution of raindrops is important because a given rainfall intensity and the drop size distribution can change significantly during a rain event (43). The type of rain (e.g., drizzle, shower, thunderstorm, widespread and stratiform, orographic, or oceanographic rains) is known to affect the frequency distribution of drop sizes (41). Drip drops or gravity drops within a canopy travel at speeds less than the terminal velocity and have low kinetic energy because of the limited fall height (15).

In natural rains of a single type, increasing rain intensity is linked with increasing number of raindrops per unit area and time (36), and also a shift in drop size distribution to larger diameters (42). The modification of rainfall by the crop canopy is of importance in splash dispersal of plant pathogens because drops produced by dripping water from the crop canopy on which rain is falling may have different effects on spore dispersal by splash compared with raindrops that impact directly on lesions bearing pycnidia with spores. The raindrop size distribution of rainfall transformed by a crop canopy is often bimodal (2), with a first mode corresponding to the raindrop size distribution of the untransformed rainfall and the second mode corresponding to the 4- to 7-mm range of drip drop diameters. In this study, the drop diameter distribution ranged from 0.2 to $2.4 \mathrm{~mm}$ outside the tree canopy and 1.0 to $7.3 \mathrm{~mm}$ inside the tree canopy. The larger drops collected inside the tree canopy contributed up to five times more rain $(199 \mathrm{~mm} / \mathrm{h})$ collected in the funnels than that $(42.5 \mathrm{~mm} / \mathrm{h})$ collected within funnels placed outside the tree canopy (Table 1). Only $2.7 \%$ of all drops reached a diameter greater than $5 \mathrm{~mm}$. Although few in number, these large drops would contribute the most volume of rain collected under a tree canopy $(16,32)$ and, consequently, would affect spore dispersal. In addition, larger drops also could disperse entire pycnidia or parts of pycnidia when the surrounding plant tissues are weathered, as was observed in the single-drop experiments (Fig. 2B, spike at the 55-mm distance from the source). In our simulated rainfall experiment, large drops removed more spores than many smaller drops generated by the small nozzle at high intensity (Table 1). Under natural conditions, drops greater than $5 \mathrm{~mm}$ usually break into smaller drops of rain before reaching the ground (2). The large drops obtained in this experiment may suggest that drops dripping from leaves did not reach terminal velocity when they were collected on water-sensitive paper. With rain generated by the $8 \mathrm{~F}$ nozzle, the difference between percent spores removed from fruit and percent spores collected in the bottles might be attributed to the difference in number of spores from each of the five fruit used in this experiment. The small nozzle $(8 \mathrm{~F})$ at high water pressure $(207 \mathrm{kPa})$ resulted in a larger amount of rain than the larger nozzle $(15 \mathrm{~F})$ at lower pressure. This is theoretically possible because a smaller nozzle at high pressure would produce many more drops, but smaller in size than those produced by a larger nozzle at low pressure (34). However this phenomenon is opposite to what is observed under natural conditions, where thunderstorms have larger drops than do showers (41).

Our results also showed that both the power law and the exponential models could be used to describe the dispersal of conidia of $B$. dothidea as well as other pathogens up to least $1 \mathrm{~m}$ outside the tree canopies (9). Overall, the dispersal gradients of $B$. dothidea were shallow $\left(B_{\mathrm{P}}<0.9\right.$ or $\left.B_{\mathrm{E}} \leq 0.06\right)$, meaning that most spores are deposited close to the source. Variation in dispersal gradient values existed among orchards and probably was due to differences in the levels of inoculum and in the size of the trees used in the three orchards. For example, trees in Glenn County were older and taller (up to $4 \mathrm{~m}$ ) than trees in Yolo and San Joaquin counties. The exponential model has some advantages over the power law because the $B_{\mathrm{E}}$ parameter (of the expo- 
nential model) has explicit units, such as $\mathrm{m}^{-1}$ or $\mathrm{cm}^{-1}$, and avoids potential interpretation problems that may arise with $B_{\mathrm{P}}$ of the power law (6). Therefore, although, with the values of $B_{\mathrm{P}}$ for the 2000-01 sampling season, it seems reasonable to conclude that $B$. dothidea had less shallow gradients in Glenn (0.877) and San Joaquin (0.753) counties than in Yolo County (0.092), the values of $B_{\mathrm{E}}$ for the exponential model mean that the rates of conidia decrease from the source are 0.061 and 0.053 conidia $/ \mathrm{cm}$ for Glenn and San Joaquin counties, respectively.

Other researchers have found that other splash-dispersed pathogens, such as Phytophthora cactorum, have gradients better described by the exponential model (13). A study by Aylor (3) with Puccinia recondita showed that dispersal is determined by the combined effect of spore deposition and dilution by atmospheric turbulence. Most of the spore dispersal studies summarized by previous researchers $(11,15,16)$ dealt with single drop or simulated rain in a controlled environment. The uniqueness of this study is that most work was based on natural rain under natural conditions. Rain-splash dispersal is critical for the development of epidemics of panicle and shoot blight. Dispersal of $B$. dothidea conidia appears to depend on the source of inoculum, rain (amount, intensity, and frequency), and plant canopy. Information from this study regarding the minimum level of rain needed for spore dispersal can be used in the development of a predictive model of the disease, occurrence of infection events, and in management strategies such as proper timing of sanitation practices (removal of cankers by pruning). Pseudothecia of $B$. dothidea have not been found in pistachio (24); therefore, inoculum is mainly water-spread conidia, and removal of old and new cankers with pycnidia of $B$. dothidea should be done before the rainy season begins in California. Also, this study provides a better understanding of the spread of inoculum of the pathogen from the various sources within and from pistachio up to at least $1 \mathrm{~m}$ from the outer tree canopies in commercial orchards.

\section{ACKNOWLEDGMENTS}

This research was funded by the California Pistachio Commission. We thank G. Driever and D. Felts for reviewing the manuscript; J. Danforth and M. Beta for technical assistance; and the pistachio growers $\mathrm{K}$. Kaplan, R. Schrum, and T. Trauba for allowing us to collect samples from their orchards.

\section{LITERATURE CITED}

1. Ahimera, N., Driever, G. F., and Michailides, T. J. 2003. Relationships among propagule numbers of Botryosphaeria dothidea, latent infections, and severity of panicle and shoot blight in pistachio orchards. Plant Dis. 87:846-853.

2. Armstrong, C. L., and Mitchell, J. K. 1988. Tree canopy characteristics and processes which affect transformation of rainfall properties. Trans. ASAE 31:1400-1409.

3. Aylor, D. E. 1987. Deposition gradients of urediniospores of Puccinia recondita near a source. Phytopathology 77:1442-1448.

4. Beisel, M., Hendrix, F. F., Jr., and Starkey, T. E. 1984. Natural inoculation of apple buds by Botryosphaeria obtusa. Phytopathology 74:335-338.

5. Britton, K. O., and Hendrix, F. F. 1986. Population dynamics of Botryosphaeria spp. in peach gummosis cankers. Plant Dis. 70:134-136.

6. Campbell, C. L., and Madden, L. V. 1990. Introduction to Plant Disease Epidemiology. John Wiley \& Sons, New York.

7. Creswell, T. C., and Milholland, R. D. 1988. Spore release and infection periods of Botryosphaeria dothidea in North Carolina. Plant Dis. 72:342346.

8. Fitt, B. D. L., and Bainbridge, A. 1983. Dispersal of Pseudocercosporella herpotrichoides spores from infected wheat straw. Phytopathol. Z. 106:214-225.

9. Fitt, B. D. L., Gregory, P. H., Todd, A. D., McCartney, H. A., and Macdonald, O. C. 1987. Spore dispersal and plant disease gradients; A comparison between two empirical models. J. Phytopathol. 118:227242.

10. Fitt, B. D. L., Lysandrou, M., and Turner, R. H. 1982. Measurement of spore-carrying droplets using photographic film and an image-analyzing computer. Plant Pathol. 31:19-24.
11. Fitt, B. D. L., McCartney, H. A., and Walklate, P. J. 1989. The role of rain in dispersal of pathogen inoculum. Annu. Rev. Phytopathol. 27:241270 .

12. Gregory, P. H. 1968. Interpreting plant disease dispersal gradients. Annu. Rev. Phytopathol. 6:189-212.

13. Grove, G. G., Madden, L. V., and Ellis, M. A. 1985. Splash dispersal of Phytophthora cactorum from infected strawberry fruit. Phytopathology 75:611-615.

14. Holtz, B. A., Sibbert, S., Kallsen, C., Michailides, T. J., Hendricks, L., Beede, B., Weinberger, G., Wylie, C., Paslay, R., and Bassett, J. 2000. Evaluation of pruning and fungicide sprays to control Botryosphaeria blight. Pages 243-247 in: Calif. Pistachio Ind. Annu. Rep. Crop Year 1999-2000. California Pistachio Commission, Fresno.

15. Huber, L., Madden, L. V., and Fitt, B. D. L. 1998. Rain-splash and spore dispersal: A physical perspective. Pages 348-370 in: The Epidemiology of Plant Diseases. D. G. Jones, ed., Kluwer Academic Publishers, Boston.

16. Madden, L. V. 1992. Rainfall and the dispersal of fungal spores. Adv. Plant Pathol. 8:39-79

17. Michailides, T. J. 1991. Pathogenicity, distribution, sources of inoculum, and infection courts of Botryosphaeria dothidea on pistachio. Phytopathology 81:566-573.

18. Michailides, T. J., and Morgan, D. P. 1992. Effects of temperature and wetness duration on infection of pistachio by Botryosphaeria dothidea and management of disease by reducing duration of irrigation. Phytopathology 82:1399-1406.

19. Michailides, T. J., and Morgan, D. P. 1993. Spore release by Botryosphaeria dothidea in pistachio orchards and disease control by altering the trajectory angle of sprinklers. Phytopathology 83:145-152.

20. Michailides, T. J., and Morgan, D. P. 1998. Update on Botryosphaeria panicle and shoot blight management programs for California pistachio. Pages 152-154 in: Calif. Pistachio Ind. Annu. Rep. Crop Year 1997-98. California Pistachio Commission, Fresno.

21. Michailides, T. J., Morgan, D. P., and Felts, D. 1997. Spread of Botryosphaeria dothidea in central California pistachio orchards. Acta Hortic. 470:582-591.

22. Michailides, T. J., Morgan, D. P., and Felts, D. 1999. BUDMON, a bud monitoring technique to predict Botryosphaeria blight in pistachio orchards. Pages 39-48 in: Calif. Pistachio Ind. Annu. Rep. Crop Year 199899. California Pistachio Commission, Fresno.

23. Michailides, T. J., Morgan, D. P., and Felts, D. G. 1999. Chemical control of Botryosphaeria blight of pistachio in California. Pages 84-100 in: Calif. Pistachio Ind. Annu. Rep. Crop Year 1998-99. California Pistachio Commission, Fresno.

24. Michailides, T. J., Morgan, D. P., and Felts, D. 2001. Collection and characterization of Botryosphaeria dothidea from various hosts and pathogenicity studies on pistachio. Univ. Calif. Kearney Agric. Cent. Plant Prot. Q. 11(1):3-8.

25. Michailides, T. J., Morgan, D. P., Felts, D. G., and Chitzanidis, A. 1998. Disease monitoring and prediction of Botryosphaeria blight in California pistachio orchards. Pages 72-79 in: Calif. Pistachio Ind. Annu. Rep. Crop Year 1997-98. California Pistachio Commission, Fresno.

26. Michailides, T. J., Morgan, D. P., and Sullivan, A. 1996. Spread of Botryosphaeria dothidea in pistachio orchards of the San Joaquin Valley. Pages 123-128 in: Calif. Pistachio Ind. Annu. Rep. Crop Year 1995-96. California Pistachio Commission, Fresno.

27. Michailides, T. J., and Ogawa, J. M. 1989. Epidemiology, epidemics, and Control of Botryosphaeria panicle and shoot blight of pistachio caused by Botryosphaeria dothidea in Northern California. Pages 99-106 in: Calif. Pistachio Ind. Annu. Rep. Crop Year 1988-89. California Pistachio Commission, Fresno.

28. Minogue, K. P. 1986. Disease gradients and the spread of disease. In: Plant Disease Epidemiology, Vol. 1: Population Dynamics and Management. K. J. Leonard and W. E. Fry, eds. Macmillan, New York.

29. Ntahimpera, N., Driever, G. F., Felts, D. G., Morgan, D. P., and Michailides, T. J. 2002. Dynamics and pattern of latent infection caused by Botryosphaeria dothidea on pistachio buds. Plant Dis. 86:282-287.

30. Ntahimpera, N., Driever, G. F., Morgan, D. P., Felts, D. G., and Michailides, T. J. 2000. Biology, epidemiology, monitoring, and control of Botryosphaeria panicle and shoot blight on pistachio (2000 Report). Pages 8-37 in: Calif. Pistachio Ind. Annu. Rep. Crop Year 2000-01. California Pistachio Commission, Fresno.

31. Ntahimpera, N., Driever, G. F., Morgan, D. P., Felts, D. G., and Michailides, T. J. 2002. Biology, epidemiology, monitoring, and control of Botryosphaeria panicle and shoot blight on pistachio (2002 Report). Pages 1-23 in: Calif. Pistachio Ind. Annu. Rep. Crop Year 2002-03. California Pistachio Commission, Fresno.

32. Ntahimpera, N., Ellis, M. A., Wilson, L. L., and Madden, L. V. 1998. Effects of a cover crop on splash dispersal of Colletotrichum acutatum conidia. Phytopathology 88:536-543.

33. Ntahimpera, N., Hacker, J. K., Wilson, L. L., Hall, F. R., and Madden, L. 
V. 1999. Characterization of splash droplets from different surfaces with a phase dropler particle analyzer. Agric. For. Meteorol. 87:201-211.

34. Ntahimpera, N., Madden, L. V., and Wilson, L. L. 1997. Effect of rain distribution alteration on splash dispersal of Colletotrichum acutatum. Phytopathology 87:649-655.

35. Ogawa, J. M., and English, H. 1991. Diseases of Temperate Zone Tree Fruit and Nut Crops. University of California, Division of Natural Resources, Davis.

36. Prupacher, H. R., and Klett, J. D. 1980. Microphysics of Clouds and Precipitation. D. Reidel Publishing Co., Holland.

37. Rice, R. E., Uyemoto, J. K., Ogawa, J. M., and Pemberton, W. M. 1985. New findings on pistachio problems. Calif. Agric. 39:15-18

38. Smith, J. A., and DeVaux, R. D. 1992. The temporal and spatial variability of rainfall power. Econometrics 3:29-53.

39. Sutton, T. B., and Boyne, J. V. 1983. Inoculum availability and pathogenic variation Botryosphaeria dothidea in apple production areas of North Carolina. Plant Dis. 67:503-506.
40. Teviotdale, B. L., Michailides, T. J., and Pscheidt, J. W., eds. 2002. Compendium of Nut Crop Diseases in Temperate Zones. The American Phytopathological Society, St. Paul, MN.

41. Ulbrich, C. W. 1983. Natural variations in the analytical form of the raindrop size distribution. J. Clim. Appl. Meteorol. 22:1764-1775.

42. Ulbrich, C. W. 1985. The effects of drop size distribution truncation on rainfall integral parameters and empirical relations. J. Clim. Appl. Meteorol. 24:580-590.

43. Ulbrich, C. W. 1994. Corrections to empirical relations derived from rainfall disdrometer data for effects due to drop size distribution truncation. Atmos. Res. 34:207-215.

44. Weaver, D. J. 1979. Role of conidia of Botryosphaeria dothidea in the spread of peach tree gummosis. Phytopathology 69:330-334.

45. Yang, X., Madden, L. V., Reichard, D. L., Wilson, L. L., and Ellis, M. A. 1992. Splash dispersal of Colletotrichum acutatum and Phytophthora cactorum from strawberry fruit by single drop impactions. Phytopathology 82:332-340. 